\title{
A PERMEABILIDADE SOCIAL DAS CARREIRAS DO ENSINO SUPERIOR
}

\author{
Maria Ligia de Oliveira Barbosa* \\ Clarissa Tagliari Santos ${ }^{* *}$
}

\begin{abstract}
Este artigo propõe-se a analisar as diferenças entre cursos pertencentes a três áreas de conhecimento (ciências biológicas, exatas e humanas) quanto à sua capacidade para oferecer maior igualdade de oportunidades no momento de expansão e diversificação do ensino superior brasileiro. O estudo foi realizado a partir dos microdados do Exame Nacional de Desempenho dos Estudantes (ENADE), combinando a nota geral da prova às respostas do questionário socioeconômico dos alunos, de forma a avaliar as associações entre o financiamento dos estudos de graduação e o desempenho e permanência nos diferentes cursos. Ao mesmo tempo em que os resultados confirmam as diferenças entre as áreas de conhecimento, também indicam a importância desses mecanismos de custeio das despesas para a finalização dos cursos. Verificam-se diferenças significativas em cada curso quanto ao desempenho associado a cada tipo de bolsa e de financiamento.

PALAVRAS-CHAVE: ensino superior, áreas de conhecimento, igualdade de oportunidades, financiamentos e bolsas.
\end{abstract}

\section{INTRODUÇÃO}

Tradicionalmente, o conhecimento é a base principal da organização dos sistemas profissionais, associando-se, assim, à forma moderna de legitimação da desigualdade social. Nesse quadro, encontra-se, em cada área de conhecimento, uma relação específica entre o grupo profissional que controla essa área e as formas sociais de transmissão, produção, desenvolvimento e distribuição social desse conhecimento. A expansão e diversificação do ensino superior no Brasil parecem associar-se a mudanças profundas no valor econômico e social dos diplomas.

Neste artigo, propõe-se a análise das diferenças entre algumas áreas de conhecimento quan-

* Doutora em Ciências Sociais. Professor adjunto da Universidade Federal do Rio de Janeiro. Vice-Presidente para América Latina do RC04 - Sociology of Education - da ISA (International Sociological Association) 2010-2014. Largo de São Francisco de Paula, 1 sala 418 - 20051070. Rio de Janeiro/ Tel - (21) 22248965 Ramal 217. mligia@ifcs.ufrj.br

** Mestre em Sociologia e Antropologia da Universidade Federal do Rio de Janeiro. Pesquisadora do Laboratório de Pesquisa em Desigualdade Social e Educação, tendo experiência na área de Sociologia, com ênfase em Sociologia da Educação. clarits@uol.com.br to à sua capacidade para lidar com os estudantes provenientes de diferentes grupos sociais, cada vez mais presentes no ensino superior, fortemente expandido dos últimos anos. Para isso, foram escolhidos oito cursos (Biologia, Fisioterapia e Medicina, entre as ciências da vida; Engenharia Civil, Engenharia Eletrotécnica e Física, entre as ciências exatas; Ciências Sociais e Direito entre as humanas) que oferecem, através dos dados do ENADE, uma enorme gama de informações, principalmente sobre o desempenho, as formas de financiamento e a condição social dos alunos. Essas diferenças são analisadas através da comparação das médias de desempenho, medido pela nota geral da prova, entre os cursos escolhidos, entre as instituições melhor e pior qualificadas em cada curso e entre os grupos de alunos com pior e melhor desempenho. Em cada uma dessas comparações considerou-se a forma de financiamento específico encontrada pelos alunos. Esperamos, assim, mostrar quais seriam as associações entre o financiamento dos estudos de graduação, o desempenho e a permanência nos diferentes cursos. Dentre essas formas de financiamento, destaca-se o PROUNI, em 
sua forma integral, por estar associado a desempenhos mais elevados na maioria das áreas. Esse efeito positivo, no entanto, é bastante variável segundo a qualidade da instituição de ensino.

\section{AEXPANSÃO E DIVERSIFICAÇÃO DO ENSI- NO SUPERIOR NO BRASIL: algumas ques- tões da pesquisa}

No final dos anos 1990 e no início do século XXI, o sistema de ensino superior (SES) brasileiro experimentou uma grande expansão, alavancada por políticas de abertura desse nível de escolarização assim como pela universalização do ensino fundamental e melhora do fluxo de estudantes no ensino médio. Esse aumento ocorreu principalmente via setor privado - atualmente responsável por 77,5\% das matrículas na educação superior (IBGE, 2009) - e trouxe consigo uma maior heterogeneidade em termos dos tipos e qualidade das instituições e também das carreiras disponíveis aos estudantes. Ao alargar a base de recrutamento, a expansão propiciou também uma diversificação na composição social dos estudantes universitários. Segundo Schwartzman (2008a), de 2001 a 2005, o total de pessoas dos três quintos de renda inferiores aumentou $97 \%$ no segmento privado do sistema de ensino superior (SES), enquanto, no segmento público, houve um aumento de $34 \%$, sinalizando que a educação superior, em geral, tornou-se menos excludente.

Ainda assim, apenas 13,9\% dos jovens brasileiros na faixa etária entre 18 e 24 anos frequenta o ensino superior (IBGE, 2009), proporção que coloca o Brasil entre os últimos países do mundo em termos de cobertura, mesmo quando comparado a nossos vizinhos da América Latina, e impõe limites à democratização desse nível de ensino. Além da pequena proporção de estudantes universitários, estudos mostram a persistência de diferenças profundas em nosso SES no que se refere à segmentação socioeconômica segundo a hierarquia das carreiras, com os alunos de melhor condição social alocados nos cursos de maior prestí- gio e qualidade (Sampaio, 2000; Vargas, 2008).

O reforço crescente das conexões entre educação e trabalho nas sociedades contemporâneas tem sido evidenciado em diversos estudos. Se essa relação deu margem ao desenvolvimento do que pode ser chamado de um ideal meritocrático, as teorias econômicas e sociológicas trataram de estabelecer bases analíticas para a sua compreensão crítica. Elemento constitutivo das teorias sobre o capital humano, desenvolvidas a partir dos economistas Gary Becker e Jacob Mincer, o estudo das relações entre escolarização, situação no mercado de trabalho e posição social constitui-se na espinha dorsal de boa parte da sociologia da educação e das desigualdades sociais, de John Goldthorpe (1997) a François Dubet et al. (2010), passando por Bills (2004), Valle Silva e Hasenbalg (2003), Regnier (2006) e Duru-Bellat (2009). Se esse tipo de estudo se estabelece principalmente a partir da economia, a sociologia vem ganhando mais espaço seja pela própria dinâmica da pesquisa, seja pelas transformações sociais. Com o desenvolvimento recente das modernas sociedades industriais, as formas de organização dessas relações sociais vêm sendo desenhadas cada vez mais fortemente em dimensões propriamente sociais. A propriedade e os rendimentos econômicos não são os determinantes exclusivos da desigualdade social, apesar de não perderem sua importância, como mostram o economista Amartya Sen (2008) e, principalmente, o sociólogo Manuel Castels (2007). É o que mostra também um texto já antigo de Pierre Bourdieu e Monique de Saint-Martin (1978) em que os autores chamam a atenção para a instituição de novos padrões de gestão e legitimação das pequenas e médias empresas. Seus proprietários refazem seu poder nessas empresas através da maior escolarização de seus filhos e netos, que, assim, ganham mais autoridade para comandar o negócio. Nesse e em outros textos de Bourdieu (particularmente La noblesse d'État-Grandes Écoles et esprit de corps, de 1989), o capital cultural certificado assume um lugar central nas disputas e na configuração das desigualdades sociais.

Diversas abordagens desenvolveram-se para 
analisar o crescente papel do conhecimento na organização das sociedades modernas. Neste artigo, trabalharemos especificamente com a abordagem da sociologia das profissões, principalmente o trabalho de Magali Larson (1977), que avança em algumas das mais relevantes questões da pesquisa sobre os grupos profissionais e ocupacionais. Em particular, ela destaca a importância da codificação, do desenvolvimento e da transmissão regulada de tipos específicos de conhecimento científico que acabam se tornando a base da identidade e do poder de cada grupo profissional. De uma perspectiva ainda mais abrangente, Grusky e seus colaboradores $(1998,2001)$ mostram a essencialidade da divisão técnica do trabalho, ou seja, das profissões e ocupações, para a construção de perspectivas analíticas que sejam capazes de compreender, em toda sua complexidade, as relações entre identidades coletivas e formas da desigualdade social.

Com todas as críticas que o trabalho de Grusky amealhou, ele tem o mérito significativo de propor uma abordagem razoavelmente sintética da constituição dos grupos sociais, reafirmando, entre os demais recursos sociais, a importância do capital cultural certificado e da especificação dos conteúdos associados a esse capital. Do ponto de vista da análise sociológica das desigualdades propriamente sociais, é imperioso considerar as distinções quanto ao tipo de conhecimento (mais ou menos abstrato e codificado, básico ou aplicado) e quanto às formas de apropriação e controle sobre ele (formação acadêmica ou profissional, aprendizado pela experiência), para que se compreenda adequadamente a natureza dos laços entre a formação superior e os valores desiguais dos diferentes diplomas.

Aqui, a contribuição de François Dubet et al. (2010) é crucial, pois, nesse estudo, os autores avançam sobre as percepções comuns ou mesmo sociológicas do papel da educação superior, escapando do determinismo e, ao mesmo tempo, do voluntarismo: nem a reprodução, nem a escola capaz de transformar o mundo. Buscam entender como as sociedades utilizam, de forma diferenciada, as qualificações escolares. O peso dos diplo- mas é muito variável, não só segundo as sociedades, mas também segundo os modos de funcionamento do sistema de ensino em todos os seus níveis e ramos, ou ainda nas diversas áreas de conhecimento.

Nesse sentido, este artigo é um primeiro passo, ainda em caráter exploratório, para tentar capturar possíveis diferenças entre algumas das grandes áreas de conhecimento (existentes e claramente demarcadas no nosso SES) quanto à sua permeabilidade a propostas de políticas públicas para a democratização do ensino superior. Buscase verificar apenas algumas diferenças entre os representantes escolhidos dessas áreas, em sua capacidade de atrair e reter estudantes oriundos tanto dos grupos mais afortunados quanto das classes populares. Esse tipo de proposta não chega, apesar de ter alguma proximidade, a uma sociologia do currículo nem discute alguns dos elementos centrais do debate contemporâneo sobre o ensino superior, como é o caso das distinções entre o público e o privado e entre o nível de qualidade de instituições frequentadas por estudantes de diferentes grupos sociais. Mas, contando também com essas contribuições, busca-se oferecer pistas iniciais para análises da participação dos grupos profissionais na construção das formas da desigualdade social. Nesse caso, essa participação seria o desenho e a ativação de mecanismos desiguais de transmissão de saberes específicos, conforme Bourdieu (1987), que, funcionando no ensino superior, poderiam fazer diferença quanto à capacidade de cada área de conhecimento para absorver os estudantes provenientes principalmente das classes populares.

Combinando diversos aspectos e diferentes abordagens ao longo das últimas décadas, o trabalho de Carlos Benedito Martins oferece um quadro complexo do ensino superior no Brasil. Um destaque importante diz respeito às dificuldades de conciliar a expansão do ensino superior, particularmente através do setor privado, e a qualidade da formação oferecida (Martins, 2009). Nessa perspectiva abrangente, já se destaca a questão em pauta: como a expansão do ensino superior se associa à sua democratização. 
Sobre a questão da democratização e seu significado em termos do acesso e da permanência dos jovens de classes populares, os trabalhos de Zago (2006) e Almeida (2007), com foco na vivência universitária em IES públicas, e a pesquisa de Santos (2011), sobre a experiência de bolsistas do PROUNI, destacam a imensa dificuldade que vai muito além do simples financiamento e do aumento das possibilidades de acesso. Nesse caso, a tese de Ana Maria A. Moreira (2010) é exemplar, oferecendo um estudo sobre os efeitos das condições institucionais na permanência dos estudantes em diferentes áreas de conhecimento.

\section{METODOLOGIA}

Esse nível mais elevado de abstração serve como uma espécie de balizamento das questões discutidas a seguir, a partir de dados empíricos: os microdados do ENADE fornecidos pelo INEP. O ENADE integra o Sinaes (Sistema Nacional de Avaliação do Ensino Superior) e tem por objetivo avaliar o rendimento dos alunos dos cursos de graduação, ingressantes e concluintes, ${ }^{1}$ em relação aos conteúdos programáticos dos cursos em que estão matriculados. O exame é obrigatório para os alunos amostrados, e a periodicidade máxima de aplicação do ENADE, em cada área do conhecimento, é trienal.

No que se refere ao conteúdo, o exame é composto por questões discursivas e de múltipla escolha, relativas a um componente de avaliação da formação geral, comum aos cursos de todas as áreas, e um componente específico de cada área. A parte referente à formação geral contribui com $25 \%$ da nota final, enquanto a referente ao componente específico contribui com $75 \%$.

Para os fins desta pesquisa, a nota final ou nota bruta da prova de cada aluno, denominada neste artigo como nota geral da prova, foi cruzada

${ }^{1} \mathrm{O}$ ENADE considera como ingressantes os estudantes que se encontram ao final do primeiro ano do curso e como "concluintes" aqueles que tiverem concluído pelo menos $80 \%$ (oitenta por cento) da carga horária mínima do currículo do curso da IES, geralmente situados no último ano do curso. com os dados referentes à situação socioeconômica dos estudantes e aos tipos de bolsas e financiamentos recebidos durante a graduação. Essas informações sobre a origem social e sobre os financiamentos e bolsas integram os microdados do questionário socioeconômico respondido pelos alunos. No que se refere aos auxílios financeiros fornecidos aos estudantes, o ENADE distingue os seguintes mecanismos: PROUNI integral; PROUNI parcial; Fundo de Financiamento ao Estudante do Ensino Superior (FIES); bolsas integrais ou parciais (inclusive descontos nas mensalidades) disponibilizadas pelas próprias IES; bolsas integrais ou parciais oferecidas por entidades externas; outros tipos de bolsas e financiamentos e nenhum tipo de auxílio.

Os cursos escolhidos para análise são oito, sendo três deles na área das ciências exatas (física, engenharia civil e engenharia eletrotécnica), três nas ciências biológicas (biologia, medicina e fisioterapia) e ainda dois cursos da área de ciências humanas (direito e ciências sociais). Buscou-se também inserir cursos que tivessem um caráter mais profissional, como engenharia, medicina e direito, e outros que fossem mais próximos das ciências básicas, como biologia e ciências sociais. Obviamente, a disponibilidade de dados de avaliação desses cursos, além da diversidade de áreas mencionada, inicialmente, foi um critério essencial.

Ressalta-se que, em todas as Tabelas construídas, os dados foram trabalhados considerando-se o seu peso amostral. As estatísticas utilizadas foram as mais simples, principalmente médias comparadas.

\section{O PROUNIE O FIES}

Considerando essa perspectiva analítica e o contexto de aumento da demanda por ensino superior e predomínio do setor privado de ensino, algumas políticas governamentais se destacam na tentativa de aumentar o acesso de camadas historicamente excluídas desse nível educacional. Este artigo não pretende analisar substantivamente os argumentos 
favoráveis ou contrários a cada uma das políticas, mil estudantes. Na Tabela 1, apresentamos os daseus vícios e virtudes, como foi dito acima. Procura- dos com a evolução da oferta de bolsas entre 2005 e mos esboçar apenas algumas distinções quanto à pre- o primeiro semestre de 2010.

sença delas nos diferentes cursos ana-

lisados. ${ }^{2}$ Assim, tratamos apenas de alguns dos aspectos importantes dessas

Tabela 1 - Evolução da oferta de bolsas do PROUNI $2005-1^{\circ}$ semestre de 2010

políticas, sem ignorar os debates que configuram as questões gerais.

O PROUNI, instituído pela Lei

$\mathrm{n}^{\mathrm{o}}$ 11.096/2005, tem como finalidade conceder bolsas de estudos integrais e parciais de $50 \%$ e $25 \%$ a estudantes

\begin{tabular}{l|r|r|r|r|r|l}
\hline & \multicolumn{1}{|c|}{$\mathbf{2 0 0 5 - 1}$ semestre de 2010} & \multicolumn{1}{c|}{$\mathbf{2 0 0 6}$} & $\mathbf{2 0 0 7}$ & $\mathbf{2 0 0 8}$ & $\mathbf{2 0 0 9}$ & $\mathbf{2 0 1 0 . 1}$ \\
\hline Parcial & 40.370 & 39.907 & 66.223 & 125.510 & 94.517 & 79.388 \\
\hline Integral & 71.905 & 98.698 & 97.631 & 99.495 & 153.126 & 85.208 \\
\hline Total & 112.275 & 138.688 & 163.854 & 225.005 & 247.643 & 164.596 \\
\hline
\end{tabular}

de baixa renda em cursos de graduação e sequenciais de formação específica. Em contrapartida, as instituições que aderem ao programa recebem isenção de alguns impostos. Os critérios para o aluno se inscrever no PROUNI são: a) não possuir diploma de ensino superior; b) ter obtido no Exame Nacional do Ensino Médio (ENEM) nota mínima de 45 pontos; $^{3} \mathrm{C}$ ) possuir renda familiar mensal per capita de até um salário mínimo e meio para obtenção de bolsas integrais e de até três salários mínimos para bolsas parciais, e d) ter estudado no ensino médio em escolas públicas ou em escolas privadas na condição de bolsista (BRASIL, 2005). O PROUNI reserva ainda parte das bolsas para pessoas com deficiência física e para pretos, pardos e indígenas, ${ }^{4}$ desde que se enquadrem nos demais critérios de seleção do programa. Também os professores da rede pública de ensino básico podem concorrer a bolsas do programa. Nesse caso, a renda familiar não é considerada. Conforme informações obtidas no site do MEC, o programa atendeu até o primeiro semestre de 2011 a mais de 800

${ }^{2}$ Nesse sentido, acompanhamos a proposta de João Feres Júnior (2008), que sugere que o debate acadêmico sobre a natureza da desigualdade não precisa estar totalmente resolvido antes para que se resolva agir. Estudos parciais ou mesmo exploratórios contribuem para que se compreendam e analisem os possíveis efeitos de políticas que visem à redução dessas desigualdades, ajudando a avançar e a aprofundar o debate acadêmico.

${ }^{3}$ Desde 2009, devido à adoção do Enem no processo seletivo de algumas instituições públicas, houve várias mudanças na estrutura e conteúdo dessa prova, sendo necessário, atualmente, atingir uma nota mínima de 400 pontos (média das cinco notas obtidas nas provas do Exame) para concorrer a uma bolsa do ProUni.

${ }^{4} \mathrm{O}$ percentual de bolsas destinadas aos cotistas é igual àquele destinado a cidadãos pretos, pardos e indígenas, em cada Estado, segundo o último censo do IBGE.
OFundo de Financiamento ao Estudante do Ensino Superior (FIES) foi instituído em 1999. É um programa do Ministério da Educação destinado a financiar a graduação de estudantes que não tenham condições de arcar com os custos de sua formação e que estejam regularmente matriculados em cursos presenciais de instituições privadas com resultados positivos nas avaliações do MEC. OFIES tem registrado uma participação cada vez maior dos estudantes do país, totalizando, em 2007, mais de 450 mil contratos ativos (BRASIL, 2009). A partir da Lei ${ }^{\circ} 11.552 / 2007$, os bolsistas parciais do Programa Universidade para Todos (PROUNI) passam a ter prioridade na obtenção de financiamento por intermédio do FIES, estabelecendo-se uma relação de complementaridade entre os dois programas, com o objetivo de criar mais um mecanismo que favoreça a permanência dos estudantes nos cursos de graduação (BRASIL, 2005).

Além desse programa, são considerados, na elaboração das tabelas, o desempenho e a inserção nos cursos daqueles estudantes que receberam bolsas integrais ou parciais (inclusive descontos nas mensalidades) disponibilizadas pelas próprias IES (BOLSAINST) ou entidades externas (BOLSAOUTIN), alunos beneficiados por outros tipos de bolsas (OUTROS) e aqueles que não contaram com nenhum tipo de auxílio (NENHUM) para custeio das despesas do curso. Como foi exposto na seção dedicada à metodologia, essa diferenciação segue estritamente a forma dos dados disponibilizados pelo INEP. 
OENADE COMO INSTRUMENTO DEAVALIAÇÃO

Desde os anos 1980, vêm sendo criados diversos sistemas de avaliação da educação brasileira em todos os seus níveis, desenvolvendo-se e aprimorando-se instrumentos e formas de análise de resultados. Como qualquer objeto de política pública na área de educação, os sistemas de avaliação foram e são objeto de intensos debates, nos quais especialistas apontam falhas, dificuldades, avanços e possibilidades de uso. Trabalhos como os de Verhine, Dantas e Soares (2006), Dias Sobrinho (2010) e Weber (2010) mostram as relações entre os diferentes processos de avaliação e a implementação das políticas públicas para o ensino superior, sendo que, nos dois primeiros casos, temos uma discussão mais técnica, e, no texto de Weber, há uma clara perspectiva sociológica sobre o funcionamento dessas políticas.

O mesmo se passa com o ENADE que, talvez por sua proximidade com a comunidade acadêmica, seja sempre submetido ao mais rigoroso escrutínio, não faltando dúvidas sobre as possibilidades do seu uso para um trabalho científico (Schwartzman, 2005).
Não desconhecemos essas críticas e menos ainda as dificuldades por elas evidenciadas, mas nos baseamos na análise de Verhine et al (2006), na qual se considera que os avanços do formato atual não resolvem todas as questões técnicas anteriores, mas permitem usar os dados. Assim, para as finalidades desse artigo, o uso dos resultados do ENADE (sempre considerando o peso amostral) permite discutir alguns dos aspectos das políticas públicas que não têm implicações relativas às especificidades e dificuldades desses exames.

\section{A ORDEM SOCIAL DOS CURSOS}

Todas as análises feitas a seguir podem se beneficiar dos dados que nos permitem esboçar uma classificação social dos frequentadores dos diferentes cursos.

Na Tabela 2, são apresentados os dados classicamente utilizados como indicadores de posição social e sua distribuição em cada curso. Assim, vemos as proporções de brancos, negros e pardos, de famílias

Tabela 2 - Informações sociais segundo o tipo de curso (\%)

\begin{tabular}{|c|c|c|c|c|c|c|c|c|}
\hline $\begin{array}{l}\text { Curso/Informa- } \\
\text { ções Sociais }\end{array}$ & Direito & $\begin{array}{l}\text { Ciências } \\
\text { Sociais }\end{array}$ & Física & $\begin{array}{l}\text { Eng. } \\
\text { Civil }\end{array}$ & $\begin{array}{l}\text { Eletrotéc- } \\
\text { nica }\end{array}$ & Biologia & Medicina & Fisioterapia \\
\hline \multicolumn{9}{|l|}{ COR } \\
\hline Brancos & 69,8 & 53,4 & 53,3 & 69,7 & 69,2 & 61,4 & 77,4 & 67,0 \\
\hline Negros & 5,0 & 11,6 & 8,7 & 5,0 & 5,2 & 6,7 & 1,9 & 5,7 \\
\hline Pardos & 22,2 & 29 & 34,4 & 22,3 & 22,2 & 29,0 & 17,4 & 23,9 \\
\hline \multicolumn{9}{|l|}{ RENDA } \\
\hline Até $3 \mathrm{SM}$ & 19,2 & 38,5 & 46,9 & 20,2 & 17,3 & 51,2 & 6,2 & 30,6 \\
\hline Entre 3 e 10 & 43,8 & 43,4 & 41,3 & 46,7 & 55,4 & 38,9 & 23,1 & 43,5 \\
\hline $\begin{array}{l}\text { Mais que } 10 \\
\text { SM }\end{array}$ & 37,0 & 18,0 & 11,9 & 33,0 & 27,2 & 10,0 & 70,8 & 25,9 \\
\hline \multicolumn{9}{|l|}{ ESC. MÃE } \\
\hline Até Ens.Fund. & 38,0 & 42,4 & 43,3 & 29,7 & 33,0 & 48,1 & 7,4 & 31,7 \\
\hline Ens. Médio & 31,3 & 32,0 & 34,7 & 33,7 & 35,7 & 30,9 & 25,6 & 37,4 \\
\hline Ens. Superior & 30,8 & 25,5 & 21,9 & 35,7 & 31,3 & 21,1 & 66,9 & 30,9 \\
\hline
\end{tabular}

Fonte: INEP: ENADE - Micro dados - Elaboração das autoras.

Os percentuais nem sempre somam 100 por arredondamentos dos mesmos. Nos casos da informação sobre cor foram omitidos os amarelos e indígenas. 
pertencentes aos três estratos de renda e de mães com diferentes níveis de escolarização nesses cursos.

O curso de medicina mostra-se claramente como aquele que recebe a elite nacional em quantidades mais substantivas: $77,4 \%$ de brancos, $66,9 \%$ de mães com ensino superior e 70,8\% com renda familiar superior a 10 salários mínimos. Numa escala bastante precária, poder-se-ia incluir, em segundo lugar, a engenharia civil, apesar de esse curso ter menor proporção de alunos provenientes de famílias com renda superior a dez salários mínimos (33,0\% contra $37,0 \%$ no Direito). Ele tem proporção semelhante de alunos brancos e a escolaridade materna é significativamente mais elevada do que a dos alunos do curso de direito, que também apresenta um conjunto mais expressivo de mães que apenas completaram o ensino fundamental (38\% contra $29,7 \%$ na engenharia civil). Pelos mesmos critérios, devemos incluir a engenharia eletrotécnica, logo a seguir ao direito, em quarto lugar.

No extremo oposto dessa distribuição, encontraríamos biologia, claramente o curso com um público mais modesto desse grupo analisado. Nesse curso, encontramos as maiores proporções de alunos provenientes de famílias com rendimento de até três salários mínimos (51,2\% ou mais da metade deles) e que têm mães com, no máximo, o ensino fundamental completo (48,1\%). O curso de física se aproxima dessa classificação, tendo, no entanto, os mesmos indicadores um pouco mais favoráveis, respectivamente 46,9\% e 43,3\%. A posição intermediária da fisioterapia e das ciências sociais, com a primeira ligeiramente acima da segunda, completa o quadro.

\section{AS VARIAÇÕES DO DESEMPENHO}

O desempenho segundo a área e por tipo de bolsa ou financiamento

Se a comparação do desempenho entre os diferentes cursos não é possível, pois as provas específicas não foram construídas de forma a expressar os conhecimentos testados em diferentes áreas numa mesma escala, o que permitiria com- parações, como mostra Schwartzman (2008b; 2011), podemos tentar inferir alguns traços do funcionamento dos cursos e da sua relação com as políticas sociais através das informações disponíveis sobre os resultados no ENADE e as fontes de financiamento. É bem verdade que poderemos estar comparando coisas muito distintas: nem todas as universidades públicas têm o mesmo nível de qualidade em seus cursos profissionais ou mesmo mais acadêmicos. Da mesma forma, há imensas diferenças entre as universidades e faculdades no setor privado. ${ }^{5}$ Nesse sentido, compararemos mais fortemente os setores diferentes do ensino superior privado - onde as bolsas e os financiamentos são mais necessários -, não discutindo a qualidade específica dos cursos públicos e privados.

Outra questão importante diz respeito aos anos distintos em que foram feitas as provas do ENADE em cada curso. Assim, o curso de direito tem dados para 2006, enquanto fisioterapia e medicina os exames foram feitos em 2007. Os demais cursos foram avaliados em 2008. Essa diferença de anos introduz pequenas modificações nos questionários, o que nos obrigou a pequenos ajustes na confecção de algumas tabelas, particularmente no recálculo dos percentuais de alunos do curso de direito que teriam recebido bolsas, FIES ou nenhum financiamento. Esse procedimento foi necessário devido ao fato de que, em 2006 e 2007, havia duas questões sobre os auxílios para custeio das despesas do curso. No primeiro caso, uma separação entre as bolsas e o FIES e, no ano seguinte, uma separação entre as informações sobre as bolsas do PROUNI e as das demais formas de bolsas e financiamentos. Em 2008, todas essas formas de auxílio foram incluídas numa única questão.

Considerando-se, então, apenas as comparações dentro de um mesmo curso, independentemente da instituição onde ele é ministrado, apresenta-se, a

${ }^{5}$ Ver Chaves (2010), Martins (2006) e Schwartzman (2008), que definem claramente as distintas posições das instituiçóes de ensino públicas e privadas quanto à sua qualidade, enfocando particularmente a necessidade e as formas da avaliação dessas instituições. No entanto, deve-se atentar para o fato de que não há qualquer correlação necessária entre baixa qualidade e ensino privado ou viceversa. Infelizmente, os baixos níveis de qualidade não constituem privilégio de um setor específico. 
Tabela $3^{6}$ com o desempenho (medido pela nota bruta geral, que reúne todas as demais notas numa úni$\mathrm{ca}^{7}$ ) médio, distinguindo-se o tipo de financiamento recebido por esse estudante.

A Tabela permite que se façam algumas observações importantes para compreender o quanto os diferentes tipos de bolsa são importantes em cada área. A ausência do PROUNI nos cursos de medicina e fisioterapia em 2007 é explicada pelas mudanças no questionário que dificultam $o$ uso dessas informações. No entanto, considerando as diversas formas de bolsas e financiamentos disponíveis, os cursos têm diferenças importantes. Inicialmente, verifica-se a proporção de bolsistas e financiados em cada curso, segundo sua condição de iniciante ou concluinte.

Verifica-se que a proporção de bolsistas e financiados é maior entre os iniciantes apenas em medicina e engenharia eletrotécnica, nesse caso, apenas ligeiramente. Na maioria dos cursos analisados, de for-

${ }^{6}$ Em cada linha, estão definidos o curso e depois a nota geral média, o número de estudantes nessa condição e

o percentual deles naquele curso. A melhor média em cada curso está sublinhada.

7 Também sobre o uso das diferentes notas, há uma boa discussão no texto de Schwartzman (2008). sagem pelo ensino superior, o chamado valor agregado pela experiência escolar. No entanto, a grande proporção de alunos bolsistas ou financiados, no caso das ciências básicas já indica a importância desses financiamentos institucionais, que são cruciais para se garantir a permanência nos cursos (Valle Silva, 1995).

Gráfico 1 - Proporção de bolsistas e financiados por curso

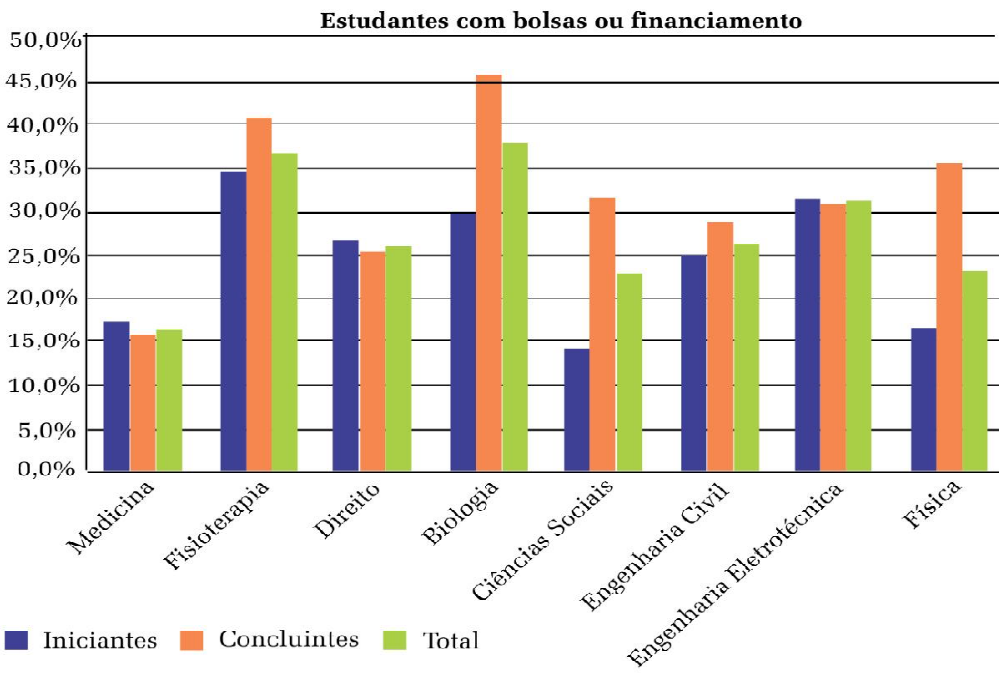

Fonte: INEP: ENADE - Microdados. Elaboração das autoras.

Gráfico 2 - Proporção dos tipos de financiamento segundo o curso

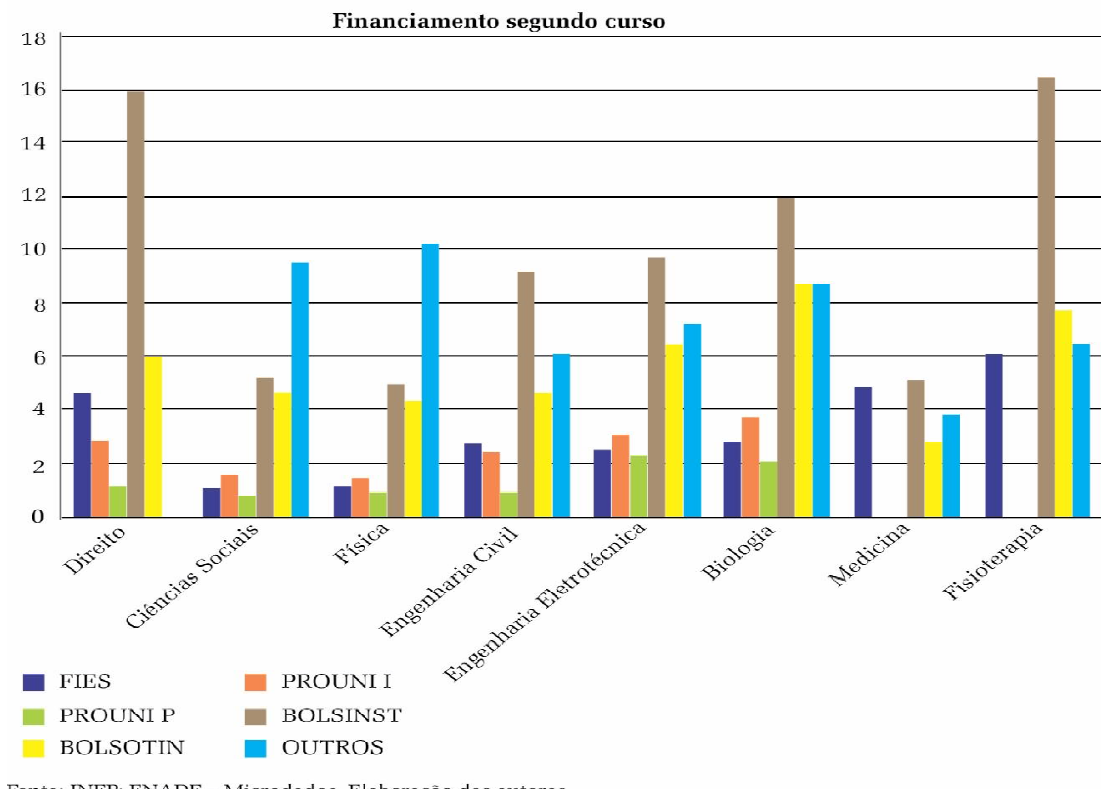

As diferenças quanto ao tipo de financiamento em cada curso são apresentadas no próximo gráfico, que exclui os estudantes que não o utilizaram. 
Maria Ligia de Oliveira Barbosa,

Clarissa Tagliari Santos

Tabela 3 - Desempenho médio (nota geral média) segundo a área e segundo o tipo de financiamento do curso

\begin{tabular}{|c|c|c|c|c|c|c|c|c|}
\hline \multirow{2}{*}{ Cursos } & \multicolumn{7}{|c|}{ Tipo de Financiamento ou Bolsa } & \multirow{2}{*}{ Total } \\
\hline & FIES & $\begin{array}{c}\text { PROUNI } \\
\text { - I }\end{array}$ & $\underset{\mathbf{P}}{\text { PROUNI - }}$ & $\begin{array}{c}\text { BOLSA } \\
\text { INST }\end{array}$ & $\begin{array}{l}\text { BOLSA } \\
\text { OUTIN }\end{array}$ & Outro(s) & Nenhum & \\
\hline \multicolumn{9}{|c|}{ Direito (2006) } \\
\hline Nota Média & $\underline{\mathbf{4 0 , 5 9}}$ & 40,34 & 35,62 & 38,66 & 37,83 & - & 39,09 & 38,50 \\
\hline Número est. & $\mathrm{N}=8968$ & $N=5511$ & $\mathrm{~N}=2022$ & $\mathrm{~N}=30042$ & $\mathrm{~N}=11121$ & & $\mathrm{~N}=138768$ & $\mathrm{~N}=196432$ \\
\hline Percentual & $4,7 \%$ & $2,9 \%$ & $1,1 \%$ & $16,0 \%$ & $5,9 \%$ & & $69,3 \%$ & $100 \%$ \\
\hline \multicolumn{9}{|c|}{ Ciências Sociais } \\
\hline Nota Média & $\mathbf{3 5 , 8 0}$ & $\underline{47,75}$ & 30,07 & 42,87 & 41,78 & 42,41 & 40,51 & 40,85 \\
\hline Número est. & $\mathrm{N}=50$ & $\mathrm{~N}=75$ & $\mathrm{~N}=41$ & $\mathrm{~N}=257$ & $N=227$ & $N=464$ & $\mathrm{~N}=3814$ & 4929 \\
\hline Percentual & $1 \%$ & $1,5 \%$ & $0,8 \%$ & $5,2 \%$ & $4,6 \%$ & $9,4 \%$ & $77,4 \%$ & $100 \%$ \\
\hline \multicolumn{9}{|l|}{ Física } \\
\hline Nota Média & 29,01 & $\underline{35,35}$ & 30,84 & 34,01 & 35,16 & 35,32 & 32,59 & 33,03 \\
\hline Número est. & $N=81$ & 99 & 66 & 348 & 306 & 726 & 5480 & 7106 \\
\hline Percentual & $1,1 \%$ & $1,4 \%$ & $0,9 \%$ & $4,9 \%$ & $4,3 \%$ & $10,2 \%$ & $77,1 \%$ & $100 \%$ \\
\hline \multicolumn{9}{|l|}{ Eng. Civil } \\
\hline Nota Média & 31,24 & $\underline{35,13}$ & 29,17 & 32,96 & 32,49 & 33,69 & 33,97 & 33,69 \\
\hline Número est. & $\mathrm{N}=427$ & $\mathrm{~N}=389$ & $N=180$ & $N=1453$ & $\mathrm{~N}=738$ & $N=946$ & $\mathrm{~N}=11767$ & $N=15901$ \\
\hline Percentual & $2,7 \%$ & $2,4 \%$ & $1,1 \%$ & $9,1 \%$ & $4,6 \%$ & $6,0 \%$ & $74 \%$ & $100 \%$ \\
\hline
\end{tabular}

Eng. Eletrotécnica

\begin{tabular}{l|r|r|r|r|r|r|r|r}
\hline Nota Média & $\mathbf{3 1 , 6 6}$ & $\underline{35,06}$ & 31,39 & 32,05 & 34,17 & 34,04 & 34,65 & 34,19 \\
\hline Número est. & $\mathrm{N}=299$ & $\mathrm{~N}=361$ & $\mathrm{~N}=277$ & $\mathrm{~N}=1178$ & $\mathrm{~N}=774$ & $\mathrm{~N}=871$ & $\mathrm{~N}=8356$ & $\mathrm{~N}=12116$ \\
\hline Percentual & $2,5 \%$ & $3,0 \%$ & $2,3 \%$ & $9,7 \%$ & $6,4 \%$ & $7,2 \%$ & $69,0 \%$ & $100 \%$ \\
\hline
\end{tabular}

Biologia

\begin{tabular}{l|r|r|r|r|r|r|r|r}
\hline Nota Média & $\mathbf{3 6 , 7 6}$ & $\underline{43,50}$ & 37,65 & 37,11 & 35,78 & 37,59 & 37,49 & 37,51 \\
\hline Número est. & $\mathrm{N}=886$ & $\mathrm{~N}=1201$ & $\mathrm{~N}=611$ & $\mathrm{~N}=3890$ & $\mathrm{~N}=2825$ & $\mathrm{~N}=2840$ & $\mathrm{~N}=20327$ & $\mathrm{~N}=32580$ \\
\hline Percentual & $2,7 \%$ & $3,7 \%$ & $1,9 \%$ & $11,9 \%$ & $8,7 \%$ & $8,7 \%$ & $62,4 \%$ & $100 \%$ \\
\hline
\end{tabular}

\section{Medicina (2007)}

\begin{tabular}{l|r|r|r|r|r|r|r|r}
\hline Nota Média & $\mathbf{4 6 , 4 1}$ & - & - & 52,65 & 48,73 & 50,07 & 48,57 & 48,73 \\
\hline Número est. & $\mathrm{N}=871$ & - & - & $\mathrm{N}=905$ & $\mathrm{~N}=493$ & $\mathrm{~N}=692$ & $\mathrm{~N}=15286$ & $\mathrm{~N}=18247$ \\
\hline Percentual & $4,8 \%$ & - & - & $5,0 \%$ & $2,7 \%$ & $3,8 \%$ & $83,8 \%$ & $100 \%$ \\
\hline
\end{tabular}

Fisioterapia (2007)

\begin{tabular}{l|r|r|r|r|r|r|r|r}
\hline Nota Média & $\underline{\mathbf{4 4 , 3 9}}$ & - & - & 42,18 & 42,13 & 40,55 & 40,96 & 41,43 \\
\hline Número est. & $\mathrm{N}=2033$ & - & - & $\mathrm{N}=5526$ & $\mathrm{~N}=2601$ & $\mathrm{~N}=2171$ & $\mathrm{~N}=21462$ & $\mathrm{~N}=33793$ \\
\hline Percentual & $6,0 \%$ & - & - & $16,4 \%$ & $7,7 \%$ & $6,4 \%$ & $63,5 \%$ & $100 \%$ \\
\hline
\end{tabular}

Fonte: INEP: ENADE - Microdados - Elaboração das autoras. 
Deve-se notar, inicialmente, o papel importantíssimo que têm as bolsas da própria instituição para os cursos de fisioterapia e direito, nos quais seriam financiados, dessa forma, aproximadamente $16 \%$ dos alunos. Nos cursos de física, ciências sociais e biologia, aparecem, de forma marcada, os outros tipos de financiamento. Dado o caráter mais acadêmico ou de ciências básicas nesses cursos, poder-se-ia especular que sejam bolsas de iniciação científica de agências oficiais federais ou estaduais. No entanto, não fica muito clara, nos dados, a distinção entre as bolsas oferecidas por outras entidades e outros tipos de financiamento, mesmo que se considere a óbvia diferença fiscal entre os dois. Seria importante compreender exatamente quais são esses diversos tipos de bolsas e financiamentos para que se analisassem adequadamente seus possíveis efeitos sobre o desempenho e as trajetórias profissionais.

Novamente o curso de medicina se destaca pela fragilidade dos mecanismos de financiamento disponíveis nessa área, o que se reflete no percentual mais elevado $(83,8 \%)$ de alunos da área que não recebem ou receberam qualquer tipo de bolsa ou financiamento extrafamiliar. Essas observações, combinadas com a dureza da seleção nesses cursos, parecem reforçar o elitismo reconhecido da formação em medicina. Realmente, os baixos níveis de financiamento público ou institucional são mais marcantes ainda pelo custo altíssimo dos estudos médicos. Some-se o fato de que alunos com acesso ao FIES obtiveram os piores resultados (média de 46,4090 contra 48,7328 da média geral) em medicina.

Também seria importante destacar que o FIES associa-se aos melhores desempenhos em dois cursos fortemente profissionalizantes: direito e fisioterapia. Em todas as demais áreas, com exceção de medicina, para a qual não foi possível obter o número de casos nessa modalidade de financiamento, é o PROUNI integral que apresenta alunos com melhor desempenho global, mesmo que isso aconteça com proporções extremamente reduzidas de estudantes (variando de 1,4\% em física e até 3,7\% em biologia). Em medicina e fisioterapia, onde não há dados sobre bolsistas do PROUNI em 2007, os melhores desempenhos vieram associados ao financiamento FIES no segundo caso, e ao financiamento da própria instituição no primeiro caso.

As carreiras das ciências da vida têm seu alto desempenho associado a diferentes tipos de financiamento. Em biologia, onde existe o PROUNI, esse tipo de bolsa integral foi associado aos melhores resultados, ao passo que o FIES fica com os melhores na fisioterapia, e as próprias instituições financiam os melhores alunos de medicina. Os piores desempenhos em biologia e medicina ficam com os alunos do FIES, enquanto o mesmo ocorre em fisioterapia entre aqueles que receberam outros tipos de financiamento. Nesse último caso, estão 6,4\% dos examinados na área, e seria importante esclarecer qual é a natureza desses outros tipos de financiamento e qual sua possível associação com resultados tão ruins. A hipótese de bolsas de iniciação científica, aventada para os casos da física, biologia e ciências sociais, talvez pudesse ser levantada aqui, apesar dos resultados opostos. Mas permanece a importância de se distinguir entre os outros tipos de bolsa e as bolsas de outras instituições.

Direito, com seus 196.432 examinados, destaca-se, de longe, como o curso mais populoso entre os que foram aqui examinados. Na mesma área de ciências humanas, as ciências sociais têm uma população ínfima, a menor desse grupo, com meros 4929 examinados. Se esse número baixo pode ser resultado de defecções institucionais ou de protestos estudantis, em todo caso, ele é um indicador do prestígio relativo dos dois campos profissionais, que, nesse quadro, aproximam-se apenas pelo fato de que os piores desempenhos estão sempre associados aos alunos que tiveram acesso ao PROUNI parcial.

No quadro das ciências exatas, todos os cursos têm seus melhores níveis de desempenho associados aos alunos com bolsas do PROUNI integral, e o pior desempenho também aparece entre aqueles que tiveram bolsas parciais no PROUNI, com exceção de física. Nesse caso, o pior desempenho é daqueles alunos com FIES. 
O desempenho segundo a área, por nível de qualificação da instituição

Considerando-se o desempenho médio por instituição em cada área, foi construído um indicador de qualidade dessas instituições, que foram distribuídas em quatro níveis. Deve-se levar em conta que essa é uma simples distribuição ordenada das instituições segundo o desempenho médio dos alunos e que cada nível de qualidade representa aproximadamente um quarto delas. Assim, o nível de maior qualidade inclui as instituições (aproximadamente 25\% delas em cada curso) com maior desempenho, ao passo que o nível de menor qualidade agruparia aquelas (25\%) com desempenho mais baixo. Apesar de discutível, esse é um indicador usado normalmente entre os economistas, como mostram os inúmeros trabalhos de Eric Hanushek. ${ }^{8}$

Em nossa análise foram consideradas apenas as posições extremas, isto é, as melhores e as piores, excluindo-se os níveis médios, de forma a tornar mais evidentes as possíveis diferenças entre as áreas. De um lado, temos as instituições com nível mais baixo de qualidade às quais se opõem as instituições com nível muito alto. Separam-se, assim, dois tipos de instituição para os quais foram observadas médias específicas de desempenho para cada tipo de financiamento do curso. As maiores médias em cada curso são sublinhadas na Tabela 4.

O fato de aparecerem algumas diferenças entre as áreas e instituições quanto ao que podemos chamar de aproveitamento das bolsas sugere questões interessantes. Assim, verificamos que o PROUNI parece incentivar fortemente o desempenho nas áreas profissionais de direito, engenharias e mesmo biologia (que não se

${ }^{8}$ Não se pode deixar de lado também a advertência do Tribunal de Contas da União, TCU, sobre a utilização de recursos públicos para financiamento de cursos mal avaliados, ou mesmo ainda sem avaliação (Brasil, 2009). Deve-se ressaltar que esse ordenamento não serve como referência para classificações de qualquer tipo, sendo apenas uma forma de distinguir instituições que conseguem melhor desempenho de seus alunos daquelas que estão na situação oposta. Não há qualquer princípio explicativo envolvido. qualificariam, exatamente, como uma área profissional) em instituições de menor qualidade. Também se verifica que os alunos com financiamento do FIES em ciências sociais (mais de 10 pontos) e fisioterapia (dois pontos e meio a mais) apresentam desempenhos bem superiores àqueles de seus colegas nessas mesmas instituições. Ainda tratando de instituições de menor qualidade, o curso de medicina parece obter retornos altos dos alunos para os quais concedem-se bolsas de estudo (quatro e meio pontos acima da média nesse nível de qualidade, na formação médica).

No extremo oposto, o PROUNI integral diferencia apenas os alunos em ciências sociais, que obtêm médias mais altas quando são bolsistas nessa modalidade. Mesmo diante dos números pouco expressivos de bolsistas, é importante comparar com os alunos das instituições mal qualificadas, onde a média obtida pelos bolsistas do PROUNI foi extremamente baixa.

Entre os estudantes de medicina, são os financiados do FIES aqueles que atingem os níveis mais elevados de desempenho nas melhores instituições. Os melhores cursos de fisioterapia conseguem os resultados mais elevados com os bolsistas da própria instituição.

Outra informação interessante, considerando-se, particularmente, a nota do TCU mencionada acima: verifica-se que, nas instituições menos qualificadas para os cursos de fisioterapia, o melhor desempenho é justamente o desses alunos com FIES. Ela traz para o debate não só a questão da qualidade ou do conceito de qualidade como também dos instrumentos legais e das formas de avaliação e mensuração do desempenho individual e institucional, na medida em que associam numa mesma instituição os níveis bem menos que satisfatórios de ensino-aprendizagem com financiamentos públicos. Na verdade, considerando-se alguns dos textos que analisam a questão do ENADE e de outras formas de avaliação, temos ainda muito caminho a percorrer para elucidar a questão premente da qualidade da própria avaliação e das possibilidades e limites dos seus usos. 
Tabela 4 -Desempenho médio segundo a área e segundo o tipo de bolsa Instituições de Baixa Qualidade (BQ) e Alta Qualidade (AQ)

\begin{tabular}{|c|c|c|c|c|c|c|c|c|c|}
\hline \multirow{2}{*}{ Cursos } & & \multicolumn{7}{|c|}{ Tipo de Bolsa ou Financiamento } & \multirow{2}{*}{ Total** } \\
\hline & & FIES & $\begin{array}{l}\text { PROUNI } \\
- \text { I }\end{array}$ & $\begin{array}{c}\text { PROUNI } \\
-\mathrm{P}\end{array}$ & $\begin{array}{l}\text { BOLSA } \\
\text { INST }\end{array}$ & $\begin{array}{l}\text { BOLSA } \\
\text { OUTIN }\end{array}$ & Outro(s) & $\begin{array}{c}\text { Nenhu- } \\
\text { m }\end{array}$ & \\
\hline \multirow{2}{*}{ Direito*BQ } & Nota média & 33.89 & $\underline{38,62}$ & 32,65 & 33,68 & 33,30 & 32,65 & 32,61 & 33,07 \\
\hline & $\%$ & 4,7 & $3,5 \%$ & $1,3 \%$ & $19,1 \%$ & $6,6 \%$ & $25,4 \%$ & $69,6 \%$ & - \\
\hline \multirow{2}{*}{ Direito*AQ } & Nota média & 43,98 & 43,97 & 40,34 & 45,14 & 43,94 & 45,98 & $\underline{46,71}$ & 46,33 \\
\hline & $\%$ & $4,0 \%$ & $1,9 \%$ & $0,4 \%$ & $11,0 \%$ & $4,5 \%$ & $17,1 \%$ & $82,2 \%$ & - \\
\hline \multirow{2}{*}{$\begin{array}{l}\text { Ciências } \\
\text { Sociais BQ }\end{array}$} & Nota média & $\underline{37,73}$ & 9,30 & 15,43 & 21,36 & 33,05 & 26,10 & 27,49 & 27,06 \\
\hline & $\%$ & $0,5 \%$ & $0,8 \%$ & $1,3 \%$ & $3,8 \%$ & $3,6 \%$ & $10,3 \%$ & $79,7 \%$ & $100(24,4 \%)$ \\
\hline \multirow{2}{*}{$\begin{array}{l}\text { Ciências } \\
\text { Sociais AQ }\end{array}$} & Nota média & 48,46 & $\underline{59,57}$ & 45,58 & 55,57 & 56,56 & 57,21 & 53,91 & 54,49 \\
\hline & $\%$ & $1,4 \%$ & $2,9 \%$ & $1,0 \%$ & $8,4 \%$ & $5,2 \%$ & $9,2 \%$ & $71,8 \%$ & $100(23,6 \%)$ \\
\hline \multirow{2}{*}{$\begin{array}{l}\text { Física } \\
\text { BQ }\end{array}$} & Nota média & 23,79 & 27,32 & 20,51 & 27,93 & 27,80 & $\underline{28,76}$ & 26,52 & 26,73 \\
\hline & $\%$ & $1,4 \%$ & $0,7 \%$ & $1,2 \%$ & $5,3 \%$ & $3,6 \%$ & $8,7 \%$ & $79,1 \%$ & $100(25,6 \%)$ \\
\hline \multirow{2}{*}{$\begin{array}{l}\text { Física } \\
\text { AQ }\end{array}$} & Nota média & 40,28 & 36,96 & 42,74 & 40,26 & $\underline{43,22}$ & 41,45 & 38,65 & 39,31 \\
\hline & $\%$ & $0,4 \%$ & $1,5 \%$ & $0,9 \%$ & $5,2 \%$ & $5,2 \%$ & $11.3 \%$ & $75,5 \%$ & $100(23,9 \%)$ \\
\hline \multirow{2}{*}{$\begin{array}{l}\text { Engenhari- } \\
\text { a Civil BQ }\end{array}$} & Nota média & 28,07 & $\underline{31,48}$ & 28,46 & 29,88 & 27,62 & 25,77 & 27,63 & 27,90 \\
\hline & $\%$ & $4,3 \%$ & $2,8 \%$ & $2,0 \%$ & $11,7 \%$ & $6,6 \%$ & $6,9 \%$ & $65,7 \%$ & $100(25,9 \%)$ \\
\hline \multirow{2}{*}{$\begin{array}{l}\text { Engenhari- } \\
\text { a Civil AQ }\end{array}$} & Nota média & 34,81 & 37,75 & 26,86 & 43,06 & 43,81 & $\underline{44,77}$ & 41,28 & 41,54 \\
\hline & $\%$ & $0,3 \%$ & $0,7 \%$ & $0,2 \%$ & $3,0 \%$ & $2,9 \%$ & $5,8 \%$ & $87,1 \%$ & $100(25,6 \%)$ \\
\hline \multirow{2}{*}{$\begin{array}{l}\text { Eng. } \\
\text { Eletrotécn- } \\
\text { ica BQ }\end{array}$} & Nota média & 26,12 & $\underline{33,93}$ & 26,71 & 27,50 & 27,89 & 27,09 & 28,34 & 28,24 \\
\hline & $\%$ & $3,1 \%$ & $4,7 \%$ & $3,0 \%$ & $11,8 \%$ & $8,3 \%$ & $8,3 \%$ & $60,8 \%$ & $100(25,4 \%)$ \\
\hline \multirow{2}{*}{$\begin{array}{l}\text { Eng. } \\
\text { Eletrotécn- } \\
\text { ica AQ }\end{array}$} & Nota média & 33,26 & 38,08 & 43,65 & 42,68 & $\underline{45,85}$ & 45,68 & 41,22 & 41,73 \\
\hline & $\%$ & $0,4 \%$ & $0,3 \%$ & $0,5 \%$ & $2,7 \%$ & $4,0 \%$ & $6,8 \%$ & $85,3 \%$ & $100(25,3 \%)$ \\
\hline \multirow{2}{*}{$\begin{array}{l}\text { Biologia } \\
\text { BQ }\end{array}$} & Nota média & 30,44 & $\underline{37,32}$ & 31,51 & 30,53 & 29,79 & 30,46 & 30,27 & 30,41 \\
\hline & $\%$ & $1,7 \%$ & $2,2 \%$ & $0,8 \%$ & $8,1 \%$ & $15,9 \%$ & $10,8 \%$ & $60,5 \%$ & $100(25,1 \%)$ \\
\hline \multirow{2}{*}{$\begin{array}{l}\text { Biologia } \\
\text { AQ }\end{array}$} & Nota média & 44,42 & 47,52 & 40,50 & 45,68 & $\underline{49,38}$ & 48,97 & 46,65 & 46,86 \\
\hline & $\%$ & $2,2 \%$ & $3,4 \%$ & $1,3 \%$ & $8,8 \%$ & $6,2 \%$ & $9,8 \%$ & $68,2 \%$ & $100(25,1 \%)$ \\
\hline \multirow{2}{*}{$\begin{array}{l}\text { Medicina } \\
\text { BQ }\end{array}$} & Nota média & 35,07 & - & - & $\underline{41,74}$ & 40,84 & 37,47 & 37,08 & 37,27 \\
\hline & $\%$ & $6,1 \%$ & & & $3,8 \%$ & $3,3 \%$ & $3,7 \%$ & $83,1 \%$ & $100(24,1 \%)$ \\
\hline \multirow{2}{*}{$\begin{array}{l}\text { Medicina } \\
\text { AQ }\end{array}$} & Nota média & $\underline{61,67}$ & - & - & 55,38 & 57,93 & 60,55 & 58,04 & 58,11 \\
\hline & $\%$ & $2,3 \%$ & & & $4,9 \%$ & $2,6 \%$ & $4,6 \%$ & $85,6 \%$ & $100(24,1 \%)$ \\
\hline \multirow{2}{*}{$\begin{array}{l}\text { Fisioterapi- } \\
\text { a BQ }\end{array}$} & Nota média & $\underline{37,09}$ & - & - & 36,30 & 36,26 & 35,67 & 33,39 & 34,43 \\
\hline & $\%$ & $4,8 \%$ & & & $15,9 \%$ & $8,3 \%$ & $7,1 \%$ & $63,8 \%$ & $100(25,3 \%)$ \\
\hline \multirow{2}{*}{$\begin{array}{l}\text { Fisioterapi- } \\
\text { a } A Q\end{array}$} & Nota média & 49,33 & - & - & $\underline{50,24}$ & 49,7340 & 49,02 & 48,82 & 49,08 \\
\hline & $\%$ & $5,1 \%$ & & & $12,0 \%$ & $5,7 \%$ & $5,6 \%$ & $71,6 \%$ & $100(24,9 \%)$ \\
\hline
\end{tabular}

Fonte: INEP: ENADE - Microdados - Elaboração das autoras.

* Totais do Direito referem-se às respostas da questão S12 (tipo de bolsa). Os dados relativos ao tipo de financiamento (S11) estão em negrito itálico.

** Nessa coluna o percentual que representa a proporção de alunos desse curso que estuda em instituições de baixa qualidade ou alta qualidade, respectivamente, foi colocado entre parênteses. 
Um quadro comparativo dos resultados nas instituições melhores e piores é apresentado a seguir:

Quadro 1 - Melhores resultados em cada curso segundo tipo financiamento

\begin{tabular}{|l|l|l|}
\hline \multicolumn{1}{|c|}{ Cursos } & \multicolumn{1}{|c|}{$\begin{array}{c}\text { Instituições } \\
\text { baixa qualidade }\end{array}$} & $\begin{array}{l}\text { Instituições alta } \\
\text { qualidade }\end{array}$ \\
\hline Direito & ProUni Integral & Nenhuma \\
\hline $\begin{array}{l}\text { Ciências } \\
\text { Sociais }\end{array}$ & FIES & ProUni Integral \\
\hline Física & Outros & $\begin{array}{l}\text { Bolsas outras } \\
\text { instituições }\end{array}$ \\
\hline $\begin{array}{l}\text { Engenharia } \\
\text { Civil }\end{array}$ & ProUni Integral & Outros \\
\hline $\begin{array}{l}\text { Engenharia } \\
\text { Eletrotécnica }\end{array}$ & ProUni Integral & $\begin{array}{l}\text { Bolsas outras } \\
\text { instituições }\end{array}$ \\
\hline Biologia & ProUni Integral & $\begin{array}{l}\text { Bolsas outras } \\
\text { instituições }\end{array}$ \\
\hline Medicina & Bolsa Instituição & FIES \\
\hline Fisioterapia & FIES & Bolsa Instituição \\
\hline
\end{tabular}

A distinção por nível de qualidade feita aqui é muito precária. No entanto, ela parece indicar que o sucesso do PROUNI está muito associado aos cursos de menor qualidade, particularmente em áreas mais voltados para uma formação focada no mercado de trabalho, sendo o curso de ciências sociais a única exceção. A presença forte das bolsas de outras entidades (CNPq, CAPES ou FAPs? Seria uma suposição razoável.) pode estar associada à formação mais acadêmica oferecida pelas universidades públicas no Brasil. Não se poderia dizer qualquer coisa sobre o papel do FIES em ciências sociais ou em fisioterapia. Entretanto, parece ser um investimento altamente valorizado também pelos estudantes que conseguem obter as melhores notas justamente num curso tão valorizado e disputado quanto o de medicina. Comparando-se a dois outros cursos fortes e tradicionais, como engenharia civil e direito, onde não aparecem mecanismos claros de financiamento, o desempenho dos alunos do FIES nos melhores cursos de medicina é um indicador favorável a essa modalidade de financiamento.

\section{Variação nas áreas por nível de desempenho individual e por tipo de bolsa}

Mudando um pouco o ângulo da análise, passa-se, aqui, a um estudo das proporções de alunos com melhor ou pior desempenho segundo o tipo de bolsa em cada curso. Da mesma forma que no caso das instituições, agrupamos os alunos de cada curso segundo o nível de desempenho individual, estabelecendo, então, uma escala de quatro pontos, em cada um dos quais teríamos um quarto dos estudantes de uma área. No primeiro nível, de melhor desempenho, estão aproximadamente $25 \%$ dos estudantes de cada curso que obtiveram as melhores notas gerais. No quarto nível, há a mesma proporção de estudantes cujas notas são mais baixas. Novamente, foram apresentados apenas os dados dos níveis mais alto e mais baixo.

Na Tabela 5, apresentam-se as proporções de alunos com baixo desempenho em cada curso, segundo o tipo de financiamento. As maiores proporções em cada curso estão sublinhadas.

A primeira constatação diz respeito à posição dúbia do PROUNI. Em se tratando de bolsistas integrais, há forte associação com bons resultados, ao passo que o PROUNI parcial parece associar-se significativamente com os desempenhos menos satisfatórios. As maiores proporções de alunos de pior desempenho encontram-se entre os que recebem bolsas parciais do PROUNI. Além disso, os melhores níveis de desempenho, em todas os cursos e em qualquer tipo de instituição, jamais estão relacionados ao PROUNI parcial.

A maior proporção $(27,8 \%$, bem acima do esperado em caso de distribuição aleatória) de alunos de medicina que têm baixo desempenho encontra-se entre aqueles que recebem financiamento FIES. Em se tratando de um curso altamente seletivo, pareceria natural que os alunos que necessitem recorrer ao FIES, alunos menos afluentes, portanto, tivessem menores níveis de desempenho, confirmando hipóteses reproducionistas ao estilo tradicional ${ }^{9}$. Ou seja: o curso de Medicina ${ }^{9}$ Entretanto não se pode esquecer que o mais alto desempenho nas instituições de maior qualidade em Medicina foi dos alunos financiados via FIES. 
Tabela 5 - Percentual de alunos com baixo desempenho por curso e tipo de financiamento

\begin{tabular}{|c|c|c|c|c|c|c|c|c|}
\hline \multirow[b]{2}{*}{ Cursos } & \multicolumn{7}{|c|}{ Tipo de Bolsa ou Financiamento } & \multirow[b]{2}{*}{ Total } \\
\hline & FIES & $\begin{array}{c}\text { PROUNI } \\
\text { - I }\end{array}$ & $\underset{P}{\text { PROUNI - }}$ & $\begin{array}{c}\text { BOLSA } \\
\text { INST }\end{array}$ & $\begin{array}{l}\text { BOLSA } \\
\text { OUTIN }\end{array}$ & Outro(s) & Nenhum & \\
\hline \multirow{2}{*}{ Direito (2006) } & 2137 & 877 & 599 & 7529 & 2897 & 27649 & 34924 & \multirow{2}{*}{$-*$} \\
\hline & $23,8 \%$ & $15,9 \%$ & $\underline{29,6 \%}$ & $25,1 \%$ & $26,0 \%$ & $25,7 \%$ & $25,2 \%$ & \\
\hline \multirow{2}{*}{$\begin{array}{l}\text { Ciências } \\
\text { Sociais }\end{array}$} & 17 & 16 & 17 & 52 & 56 & 136 & 911 & \multirow{2}{*}{$\begin{array}{r}1205 \\
24,4 \%\end{array}$} \\
\hline & $34,0 \%$ & $21,1 \%$ & $\underline{42,5 \%}$ & $20,2 \%$ & $24,7 \%$ & $29,3 \%$ & $23,9 \%$ & \\
\hline \multirow{2}{*}{ Física } & 28 & 11 & 24 & 87 & 73 & 154 & 1418 & \multirow{2}{*}{$\begin{array}{r}1795 \\
25,3 \%\end{array}$} \\
\hline & $35,0 \%$ & $11,2 \%$ & $\underline{36,4 \%}$ & $25,0 \%$ & $23,9 \%$ & $21,2 \%$ & $25,9 \%$ & \\
\hline \multirow{2}{*}{ Eng. Civil } & 129 & 71 & 64 & 347 & 213 & 261 & 2917 & \multirow{2}{*}{$\begin{array}{r}4002 \\
25,2 \%\end{array}$} \\
\hline & $30,2 \%$ & $18,2 \%$ & $\underline{35,6 \%}$ & $23,9 \%$ & $28,9 \%$ & $27,6 \%$ & $24,8 \%$ & \\
\hline \multirow{2}{*}{$\begin{array}{l}\text { Eng. } \\
\text { Eletrotécnica }\end{array}$} & 94 & 64 & 88 & 343 & 218 & 243 & 1991 & \multirow{2}{*}{$\begin{array}{r}3041 \\
25,1 \%\end{array}$} \\
\hline & $31,5 \%$ & $17,7 \%$ & $\underline{31,8} \%$ & $29,1 \%$ & $28,2 \%$ & $27,9 \%$ & $23,8 \%$ & \\
\hline \multirow{2}{*}{ Biologia } & 200 & 105 & 125 & 969 & 932 & 852 & 4959 & \multirow{2}{*}{$\begin{array}{r}8142 \\
\mathbf{2 5 , 0} \%\end{array}$} \\
\hline & $22,6 \%$ & $8,7 \%$ & $20,5 \%$ & $24,9 \%$ & $\underline{33,0} \%$ & $30,0 \%$ & $24,4 \%$ & \\
\hline \multirow{2}{*}{$\begin{array}{l}\text { Medicina } \\
(2007)\end{array}$} & 242 & - & - & 158 & 123 & 143 & 3912 & \multirow{2}{*}{$\begin{array}{r}4578 \\
25,1 \%\end{array}$} \\
\hline & $\underline{27,8} \%$ & & & $17,5 \%$ & $24,9 \%$ & $20,7 \%$ & $25,6 \%$ & \\
\hline \multirow{2}{*}{$\begin{array}{l}\text { Fisioterapia } \\
(2007)\end{array}$} & 332 & - & - & 1285 & 561 & 592 & 5712 & \multirow{2}{*}{$\begin{array}{r}8482 \\
25,1 \%\end{array}$} \\
\hline & $16,3 \%$ & & & $23,3 \%$ & $21,6 \%$ & $\underline{27,3} \%$ & $26,6 \%$ & \\
\hline
\end{tabular}

Fonte: INEP: ENADE - Microdados - Elaboração das autoras.

*Não é possível definir os totais no Direito pois os dados de bolsas e financia mentos são apresentados separadamente e sem que se possa estabelecer uma relação clara entre os dois (Questões S11- FIES e outros tipos de financiamento; e S12 para demais informações).

parece ter dificuldades para oferecer efetivamente algum tipo de igualdade de oportunidades, mas essa capacidade pode ter variações institucionais importantes. Esse parece ser, mesmo assim, um tipo de curso em que o ensino superior reafirmaria a força dos determinismos sociais, em que a origem social praticamente define o destino social (Valle Silva; Hasenbalg, 2003).

Nesse sentido, a fisioterapia destaca-se pela elevada proporção (33,2\%) de bolsistas FIES dentre seus alunos de melhor desempenho, como se vê na Tabela 6. Nela, são apresentadas as proporções de alunos de melhor desempenho em cada curso e segundo o tipo de financiamento (novamente são sublinhadas as maiores proporções). Também é elevada a proporção de bons alunos de direito, com o mesmo tipo de financiamento. Man- tendo-se a mesma linha de análise, teríamos, nesses cursos, um nível ligeiramente maior igualdade de oportunidades propiciada a partir da escola.

Reitera-se a necessidade de especificação das bolsas de outras instituições: entre esses bolsistas, encontramos os piores desempenhos em biologia e os melhores em física. Como são dois cursos que congregam os alunos de origem social mais modesta, os mecanismos de financiamento da formação superior certamente são um componente essencial na produção de igualdade de oportunidades.

A força do PROUNI integral, nas três grandes áreas, humanas, biológicas e exatas, é decisiva, particularmente para cursos mais acadêmicos ou de ciências básicas, como ciências sociais e biologia. Acrescente-se a isso o fato de que, nesses cursos, uma boa parte dos egressos tem seu maior 
Maria Ligia de Oliveira Barbosa,

Clarissa Tagliari Santos

Tabela 6 - Percentual de alunos com alto desempenho por curso e tipo de financiamento

\begin{tabular}{|c|c|c|c|c|c|c|c|c|}
\hline \multirow{2}{*}{ Cursos } & \multicolumn{7}{|c|}{ Tipo de Bolsa ou Financiamento } & \multirow{2}{*}{ Total } \\
\hline & FIES & $\begin{array}{c}\text { PROUNI } \\
\text { - I }\end{array}$ & $\underset{P}{\text { PROUNI - }}$ & $\begin{array}{c}\text { BOLSA } \\
\text { INST }\end{array}$ & $\begin{array}{l}\text { BOLSA } \\
\text { OUTIN }\end{array}$ & Outro(s) & Nenhum & \\
\hline \multirow{2}{*}{ Direito (2006) } & 2371 & 1393 & 267 & 6930 & 2250 & 25487 & 35878 & \multirow{2}{*}{ * } \\
\hline & $\underline{26,4 \%}$ & $25,3 \%$ & $13,2 \%$ & $23,1 \%$ & $20,2 \%$ & $23,7 \%$ & $25,9 \%$ & \\
\hline \multirow{2}{*}{$\begin{array}{l}\text { Ciências } \\
\text { Sociais }\end{array}$} & 14 & 34 & 9 & 67 & 69 & 177 & 877 & \multirow{2}{*}{$\begin{array}{r}1247 \\
25,3 \%\end{array}$} \\
\hline & $28,0 \%$ & $\underline{44,7 \%}$ & $22,5 \%$ & $26,0 \%$ & $30,4 \%$ & $38,1 \%$ & $23,0 \%$ & \\
\hline \multirow{2}{*}{ Física } & 10 & 23 & 15 & 97 & 106 & 233 & 1281 & \multirow{2}{*}{$\begin{array}{r}1765 \\
24,8 \%\end{array}$} \\
\hline & $12,5 \%$ & $23,5 \%$ & $22,7 \%$ & $27,9 \%$ & $\underline{34,6 \%}$ & $32,1 \%$ & $23,4 \%$ & \\
\hline \multirow{2}{*}{ Eng. Civil } & 73 & 107 & 21 & 302 & 176 & 247 & 3050 & \multirow{2}{*}{$\begin{array}{r}3976 \\
\mathbf{2 5 , 0} \%\end{array}$} \\
\hline & $17,1 \%$ & $\underline{27,4 \%}$ & $11,7 \%$ & $20,8 \%$ & $23,8 \%$ & $26,1 \%$ & $25,9 \%$ & \\
\hline \multirow{2}{*}{$\begin{array}{l}\text { Eng. } \\
\text { Eletrotécnica }\end{array}$} & 48 & 101 & 37 & 196 & 191 & 205 & 2245 & \multirow{2}{*}{$\begin{array}{r}3023 \\
\mathbf{2 5 , 0} \%\end{array}$} \\
\hline & $16,1 \%$ & $\underline{28,0 \%}$ & $13,4 \%$ & $16,6 \%$ & $24,7 \%$ & $23,5 \%$ & $26,9 \%$ & \\
\hline \multirow{2}{*}{ Biologia } & 178 & 493 & 142 & 867 & 665 & 751 & 5040 & \multirow{2}{*}{$\begin{array}{r}8136 \\
\mathbf{2 5 , 0} \%\end{array}$} \\
\hline & $20,1 \%$ & $\underline{41,0 \%}$ & $23,2 \%$ & $22,3 \%$ & $23,5 \%$ & $26,5 \%$ & $24,8 \%$ & \\
\hline \multirow{2}{*}{$\begin{array}{l}\text { Medicina } \\
(2007)\end{array}$} & 168 & - & - & 283 & 117 & 185 & 3798 & \multirow{2}{*}{$\begin{array}{r}4551 \\
24,9 \%\end{array}$} \\
\hline & $19,3 \%$ & & & $\underline{31,3 \%}$ & $23,7 \%$ & $26,7 \%$ & $24,8 \%$ & \\
\hline \multirow{2}{*}{$\begin{array}{l}\text { Fisioterapia } \\
(2007)\end{array}$} & 674 & - & - & 1473 & 655 & 516 & 5121 & \multirow{2}{*}{$\begin{array}{r}8439 \\
25,0 \%\end{array}$} \\
\hline & $\underline{33,2 \%}$ & & & $26,7 \%$ & $25,2 \%$ & $23,8 \%$ & $23,9 \%$ & \\
\hline
\end{tabular}

Fonte: INEP: ENADE - Microdados - Elaboração das autoras.

*Não é possível definir os totais no Direito pois os dados de bolsas e financia mentos são apresentados separadamente e sem que se possa estabelecer uma relação clara entre os dois (Questões S11- FIES e outros tipos de financiamento; e S12 para demais informações).

mercado de trabalho no ensino básico. Mas também para as engenharias civil e eletrotécnica, cursos claramente profissionais, o PROUNI integral parece representar um apoio fundamental para os bons níveis de desempenho.

\section{OS FINANCIAMENTOS, AS BOLSAS E AS ÁREAS: considerações finais}

Um dos objetivos principais deste artigo seria verificar o quanto as diferentes áreas de conhecimento seriam permeáveis às políticas sociais ou o quanto cada uma dessas áreas seria capaz de funcionar como uma instituição escolar que fosse capaz de garantir a seus alunos, independentemente de sua posição social, níveis elevados de aprendizagem.
O que se verifica é que os cursos atendem diferencialmente a esse princípio de igualdade de oportunidades quando se analisa a presença e os possíveis efeitos das diferentes formas de financiamento público e institucional.

De uma maneira geral, pode-se afirmar que os diversos sistemas de bolsas e financiamentos para o ensino superior apresentam resultados bastante satisfatórios: seja o PROUNI, que tem os alunos com melhores resultados nas diferentes áreas, seja o financiamento via FIES, no caso de direito e fisioterapia, ou bolsas da própria instituição para medicina. Não estamos diante de tautologias pois nem todos os tipos de bolsas e financiamento estão associados ao desempenho. Além disso, parece haver uma influência importante do tipo de instituição de ensino sobre as possibilidades de apro- 
veitamento e sucesso na aprendizagem segundo os tipos de financiamento. De qualquer forma, essa seria uma indicação de que o investimento em alguns estudantes vale a pena tanto do ponto de vista institucional, com a valorização de uma determinada instituição pela qualidade dos seus alunos, quanto do ponto de vista estritamente pessoal ou individual, na medida em que esses financiamentos podem significar a base de uma carreira profissional promissora. Se não podemos comparar o desempenho dos diferentes cursos, a constatação da importância das bolsas e dos financiamentos para a sua finalização é evidente, reforçando essa hipótese do papel crucial desses mecanismos para o ensino superior. Esse argumento fica ainda mais claro quando se verifica que, no curso de biologia, aquele que tem os mais baixos indicadores de posição social, encontra-se o maior percentual (46\%) de alunos financiados ou com bolsas que concluíram seu curso.

Um problema aparece quando se analisam as diferenças de desempenho entre os distintos tipos de financiamento segundo a qualidade das instituições. OPROUNI integral parece ter importantes efeitos na melhoria de desempenho nos cursos de direito, engenharias e biologia nas instituições de baixa qualidade. É como se essa política pública fosse um incentivo ao aprendizado, mesmo que as condições institucionais sejam desfavoráveis. As bolsas da própria instituição parecem cumprir o mesmo papel no caso dos cursos piores de medicina.

No caso de instituições de alta qualidade, desenha-se uma oposição bastante interessante dentre os cursos mais voltados para o mercado profissional. Enquanto, em Direito, os melhores desempenhos são apresentados pelos alunos que são exclusivamente financiados pelas próprias famílias, sem qualquer apoio institucional, nos bons cursos de medicina, os melhores alunos são aqueles com financiamento do FIES. Também nessas melhores instituições, o PROUNI integral parece dar bons resultados apenas em ciências sociais. Essas distinções entre as áreas de conhecimento, quando se discutem instituições de mais alta qua- lidade, parecem indicar que, talvez aí, nessas instituições melhores, as especificidades das formas de organização e transmissão do conhecimento possam mostrar alguns dos seus efeitos. Mesmo assim, justamente pela impossibilidade de comparar os níveis de desempenho entre essas áreas, esta é, no máximo, uma hipótese a ser investigada.

Outro efeito positivo dos diversos tipos de financiamento e de bolsas aparece na proporção de bons alunos que fizeram parte desses diferentes programas, com destaque especial novamente para o PROUNI integral. Mas o caso do FIES em medicina, um dado chama a atenção: responsável pelo melhor desempenho entre os alunos das melhores instituições, entre os seus financiados encontra-se também a maior proporção de desempenhos piores. O oposto acontece em fisioterapia e direito: são os alunos do FIES os que têm maiores proporções de melhor desempenho.

Nesse quadro, parece haver um reforço importante quanto às qualidades do PROUNI integral e quanto às dificuldades associadas à sua forma parcial. Já o FIES tem resultados por vezes paradoxais, pois podemos encontrar um conjunto de efeitos distintos, seja da instituição, seja do funcionamento da área de conhecimento, seja ainda do próprio mecanismo de financiamento.

Quanto às bolsas da própria instituição, verifica-se um efeito bastante positivo em medicina. As demais bolsas e outros tipos de financiamento apresentam resultados que não permitem maiores análises, mesmo porque é pouco clara a distinção entre esses tipos.

Os diferentes cursos variam em sua permeabilidade às políticas sociais e em sua capacidade de oferecer maior igualdade de oportunidades. Essa variação parece estar associada, inicialmente, à origem social dos alunos. Usando a proporção de financiados (bolsas e financiamentos) entre os formandos, chega-se a uma escala que é quase oposta àquela que existe quando se considera a origem social dos alunos de cada área. Cursos em que os alunos têm posição social mais elevada têm menores proporções de alunos concluintes com bolsas ou financiamentos 
institucionais e públicos. O contrário é verdade: o curso de biologia, com os alunos de origem social mais modesta, é aquele com maior percentual de concluintes que receberam bolsas.

Quadro 2 - "Ordem social" dos cursos e "Ordem das Proporções de Financiamento"

\begin{tabular}{|l|l|}
\hline \multicolumn{1}{|c|}{$\begin{array}{c}\text { Ordem social" dos } \\
\text { cursos }\end{array}$} & $\begin{array}{c}\text { "Ordem das Proporçóes } \\
\text { de Financiamento" }\end{array}$ \\
\hline Medicina & Biologia \\
\hline Eng. Civil & Fisioterapia \\
\hline Direito & Física \\
\hline Eng. Eletrotécnica & Ciências Sociais \\
\hline Fisioterapia & Eng. Eletrotécnica \\
\hline Ciências Sociais & Eng. Civil \\
\hline Física & Direito \\
\hline Biologia & Medicina \\
\hline
\end{tabular}

Fonte: INEP: ENADE - Microdados- Elaboração das autoras.

Esse ordenamento social dos cursos foi feito a partir dos dados sociais dos alunos de cada um deles, considerando-se tanto os níveis de rendimento quanto à escolaridade da mãe, como foi discutido na seção "A ordem social dos cursos" nesse artigo. Já a ordem das proporções de financiamento, o percentual de alunos que recebem bolsas foi feita através de um simples ordenamento desses percentuais.

Outro fator parece ser ligado ao mercado de trabalho: cursos que formam alunos para um mercado bastante profissionalizado e até regulado, como o caso de engenharias, direito e medicina, parecem ter menor necessidade de algum tipo de financiamento para incentivar ou auxiliar a conclusão dos cursos. Por outro lado, cursos das ciências básicas, de caráter mais acadêmico, ou que sejam mais voltados para o atendimento do ensino médio ou fundamental, apresentam taxas expressivamente maiores de alunos financiados entre os seus concluintes. Dessa perspectiva, a posição da fisioterapia - claramente mais profissionalizante-parece indicar que o peso do fator origem social foi mais forte, aumentando a necessidade de financiamentos entre seus formandos, contrariamente ao que aconteceu nas ciências sociais.
Essa distinção entre dois fatores - origem social e educação -, como foi analisada tanto nos trabalhos de Valle Silva e Hasenbalg (2003) como no de Ferreira (2000), parece ser uma das disputas sociais mais importantes na configuração das hierarquias brasileiras. Ferreira (2000) destaca a importância do que ele chama de fatores políticos na definição do peso que a educação pode ter na formação das hierarquias sociais, chamando a atenção para o fato de que as classes médias e a elite teriam recursos sociais e políticos maiores e mais fortes. Esse autor sinaliza para as possíveis estratégias desses grupos visando à manutenção de sua posição privilegiada. Se não existe qualquer evidência de tais estratégias, a manutenção de algumas posições privilegiadas parece razoavelmente clara nos dados analisados.

Os dados aqui analisados não permitem verificar distinções conclusivas entre as áreas do conhecimento no que diz respeito à sua maior ou menor capacidade de oferecer igualdade de oportunidades. No entanto, aparecem diferenças importantes quanto ao desempenho, associado, em cada curso, aos diferentes tipos de bolsa e de financiamento. O PROUNI tem efeitos positivos na maioria das áreas analisadas: biologia, ciências sociais, física, engenharias civil e eletrotécnica. Mas esse efeito existe quando se trata da sua forma integral, pois o PROUNI parcial está associado fortemente a piores níveis de desempenho em várias áreas. Além disso, esse programa sofre variações, distinguindo-se, principalmente, nas instituições de maior e menor qualidade, reforçando a necessidade de avaliações mais finas do seu funcionamento. Os efeitos positivos associados ao FIES, nos cursos de direito e fisioterapia, são ainda reforçados pelo fato de que, nas escolas de medicina de melhor qualidade, ele é a forma de financiamento dos alunos mais bem sucedidos.

Se algumas dessas diferenças parecem mais associadas à origem social dos alunos, indicando ainda o peso dos critérios patrimonialistas no ensino superior brasileiro, outras podem ser um indicador de que haveria traços de modernidade nesse sistema, com espaço para jogos sociais mais 
modernos, em que conhecimentos diferenciados e formas institucionais diversas são relevantes.

Nesse sentido, o artigo não dá respostas acabadas, pois cada um dos ângulos discutidos do problema deixa ainda várias possibilidades e caminhos de pesquisa. Seja do ponto de vista curricular em cada curso - programas disciplinares expressam, normalmente, a visão dominante daquela disciplina -, seja do ponto de vista das formas administrativas e pedagógicas de organizar o ensino, a pesquisa ainda engatinha no estabelecimento das conexões entre formação superior e desigualdade social. Este texto visa apenas a contribuir para o debate, buscando ressaltar a importância da distinção clara entre os significados sociais da divisão técnica do trabalho e do conhecimento.

(Recebido para publicação em 19 de agosto de 2011) (Aceito em 05 de dezembro de 2011)

\section{REFERÊNCIAS}

ALMEIDA, Wilson Mesquita de. Estudantes com desvantagens econômicas e educacionais e fruição da universidade. Caderno CRH: Centro de Recursos Humanos da UFBA, Salvador, n.49, p.35-46, jun./abr., 2007.

AMARAL, Daniela Pereira; OLIVEIRA, Fátima Bayma. O ProUni e a conclusão do ensino superior: questões introdutórias sobre os egressos do programa na Zona Oeste do Rio de Janeiro. Ensaio: avaliação políticas públicas educação, Rio de Janeiro, v.19, n.70, p.21-42, jan./mar., 2011. Malden,MA: Blackwell Publishing, 2004. p.250

BOURDIEU, P.; SAINT-MARTIN, M. Le patronat. Actes de la Recherche en Sciences Sociales, Paris, n. 20/21, p.382, mar./avr., 1978.

La noblesse d'État: grandes écoles et esprit de corps. Paris: Les Éditions de Minuit, 1989.

Sistemas de ensino e sistemas de pensamento. In: BOURDIEU, P. A Economia das trocas simbólicas. São Paulo: Ed. Perspectiva, 1987.

BRASIL. Lei $n^{\circ}$ 11.096, de 13 de jan. de 2005. Institui o Programa Universidade para Todos - ProUni, regula a atuação de entidades beneficentes de assistência social no ensino superior altera a Lei $\mathrm{n}^{0} 10.891$, de 9 de julho de 2004, e dá outras providências. Disponível em: www2.camara.gov.br/legin/fed/lei/2005/lei-11096-13-janeiro-2005-535381-norma-pl.html. Acesso em: 10 jun. 2008.

Tribunal de Contas da União. Relatório de auditoria operacional: Programa Universidade para Todos (ProUni) e Fundo de Financiamento ao Estudante do Ensino Superior (FIES). Relator Ministro José Jorge. Brasília: TCU, 2009. 145 p. Disponível em: http://portal2.tcu.gov.br/portal/page/portal/ TCU/comunidades/programas_governo/areas_atuacao/
educacao/Relat\%C3\%B3rio\%20de\%20auditoria_Prouni.pdf. Acesso em: 13 mar. 2011

CASTELS, Manuel. A era da informação. Rio de Janeiro: Paz e Terra, 2007. 2v

CHAVES, Vera Lucia Jacob. Expansão da privatização/ mercantilização do ensino superior brasileiro: a formação dos oligopólios. Educação e Sociedade, Campinas, v.31, n.111, p.481-500, abr./jun., 2010

DIAS SOBRINHO, José. Avaliação e transformações da educação superior brasileira (1995-2009): do Provão ao Sinaes. Avaliação, Campinas, v.15, n.1, p.195-224, mar., 2010

DUBET, François et al. Les sociétés et leur école: emprise du diplome et cohésion sociale. Paris: Éditions du Seuil, 2010

DURU-BELLAT, Marie. Le mérite contre la justice. Paris: Les presses de Sciences Po, 2009. (Coll. nouveau débats)

FERES JÚNIOR, João. Ação Afirmativa: política pública e opinião. Sinais Sociais, n.8, p.38-77, 2008.

FERREIRA, Francisco. Os determinantes da desigualdade de renda no Brasil: luta de classes ou heterogeneidade educacional. In: HENRIQUES, Ricardo (Org.) Desigualdade e pobreza no Brasil. Rio de Janeiro: IPEA, 2000.

GOLDTHORPE, John. Problems of 'meritocracy'. In: HALSEY, A. et al (Ed.) Education: culture, economy, society. Oxford: Oxford University Press, 1997.

GRUSKY, D.; WEEDEN, K. Decomposition without death: a research agenda for a new class analysis. Acta Sociologica, London, Sage, v.44, n.3, p.203-219, 2001.

; SORENSEN, J. Can class analysis be salvaged? American Journal of Sociology, Chicago, v.103, n.5, p.11871234, 1998.

IBGE. Síntese de Indicadores Sociais: uma análise das condições de vida da população brasileira 2009. Rio de Janeiro, 2009

LARSON, M.S. The rise of professionalism. Berkeley: University of California Press, 1977.

MARTINS, Carlos Benedito. Uma reforma necessária. Educação e Sociedade, Campinas, v.27, n. 96, Esp., p.10011020, out., 2006.

A reforma universitária de 1968 e a abertura para o ensino superior privado no Brasil. Educação e Sociedade, Campinas, v.30, n.106, p15-35, jan./abr., 2009

MOREIRA, Ana Maria Albuquerque. Fatores institucionais e desempenho acadêmico no ENADE: um estudo dos cursos de biologia, engenharia civil, história e pedagogia. 2010. 251f. Tese (Doutorado em Educação) - Universidade de Brasília, 2010.

RÉGNIER, Karla von Doellinger. O que conta como mérito no processo de seleção de gerentes e executivos no Brasil: uma análise baseada na oferta de empregos nos anúncios classificados. 2006. 327f. Tese (Doutorado em Sociologia) - Programa de Pós-Graduação em Sociologia e Antropologia da Universidade Federal do Rio de Janeiro., 2006.

SAMPAIO, Helena. O ensino superior no Brasil: o setor privado. São Paulo: Fapesp/Hucitec, 2000.

SANTOS, Clarissa Tagliari. A chegada ao ensino superior: o caso dos bolsistas do ProUni da PUC-Rio. 2011. 149f. Dissertação (Mestrado em Sociologia) - Programa de PósGraduação em Sociologia e Antropologia da Universidade Federal do Rio de Janeiro, 2011.

SCHWARTZMAN, Simon. O enigma do ENADE. 2005 Disponível em: www. schwartzman.org.br/simon/ enade.pdf. Acesso em: 23 dez. 2011. 
Maria Ligia de Oliveira Barbosa,

Clarissa Tagliari Santos

. A questão da inclusão social na universidade brasileira. In: PEIXOTO, Maria do C. L; ARANHA, Antônio V. (Org.) Universidade pública e inclusão social: experiência e imaginação. Belo Horizonte: Editora UFMG, 2008a.

O "conceito preliminar" e as boas práticas de avaliação do ensino superior. 2008b. Disponível em; www.schwartzman.org.br/simon/prelim.pdf. Acesso em: 23 dez. 2011

Para além do Sinaes. In: REUNIÃO DA ASSOCIACAO BRASILEIRA DE AVALIAÇAO EDUCACIONAL, 6. Fortaleza, 2011. Disponível em: www. schwartzman.org.br/ simon/2011_sinaes.pdf.

SEN, Amartya. Desigualdade reexaminada. Rio de Janeiro: Record, 2008.

VALLE SILVA, N. do; HASENBALG, C. (Org.) Origens $e$ destinos: desigualdades sociais ao longo da vida. Rio de Janeiro: Topbooks, 2003.

. Algumas observações sobre a graduacão em Ciências Sociais e o Laboratório de Pesquisa Social. In PESSANHA, Elina; VILLAS-BÔAS, Glaucia. (Org.) Ciên- cias sociais: ensino e pesquisa na graduação. Rio de janeiro: J.C. Editora, 1995.

VARGAS, Hustana Maria. Represando e distribuindo distinção: a barragem do ensino superior. 2008. Tese (Doutorado em Educação) - Pontifícia Universidade Católica do Rio de Janeiro,2008.

VERHINE, Robert Evan; DANTAS, Lys Maria Vinhaes; SOARES, José Francisco. Do provão ao Enade: uma análise comparativa dos exames nacionais utilizados no Ensino Superior Brasileiro. Ensaio: avaliacão políticas públicas educação, Rio de Janeiro, v.14, n.52, p.291-310, jul./set. 2006

WEBER, Silke. Avaliação e regulação da educação superior: conquistas e impasses. Educação e Sociedade, Campinas, v.31, n.113, p.1247-1269, out./dez. 2010.

ZAGO, Nadir. Do acesso à permanência no ensino superior: percursos de estudantes universitários de camadas populares. Revista Brasileira de Educação, Rio de Janeiro, v.11, n.32, p.226-237, maio/ago. 2006. 


\section{THE SOCIAL PERMEABILITY OF THE CAREERS ON HIGHER EDUCATION}

\author{
Maria Ligia de Oliveira Barbosa \\ Clarissa Tagliari Santos
}

This article propose the analyses the differences between courses belonging to three areas of knowledge (biological, exact and human sciences) as theirs capability to offer greater equality of opportunities at the moment of expansion and diversification in Brazilian higher education. The study was conducted from micro-data of the National Exam of students Performance (ENADE), combining the general marks of the exam the answers of the socio-economical questionnaire of the students, in such a way to evaluate the association between under graduate student's grants and the performance and the staying in different courses. At the same time that the results confirm the differences between fields of knowledge it also indicates the importance of those tools of financing expenses for the conclusion of the course. It was verified that different significant in each course in relation to the performance associated to each type of scholarship and financing,

Key Words: higher eduction, fields of knowledge, equality of opportunities, financing and scholarship.

\section{LA PERMÉABILITÉ SOCIALE DES CARRIÈRES DE L'ENSEIGNEMENT SUPÉRIEUR}

\author{
Maria Ligia de Oliveira Barbosa \\ Clarissa Tagliari Santos
}

Cet article présente les différences entre les cours liés à trois domaines de la connaissance (sciences biologiques, exactes et humaines). Il se propose d'analyser leur capacité d'offrir une plus grande égalité de chance, au moment de l'expansion et de la diversification de l'enseignement supérieur au Brésil. Létude est réalisée à partir des micro données de l'ENADE- Exame Nacional de Desempenho dos Estudantes (Examen National des Connaissances des Étudiants). Elle met en relation la note finale de l'Examen et les réponses au questionnaire socioéconomique des étudiants. Elle évalue la relation entre le financement des études universitaires et les résultats et la permanence dans les différents cours. Alors que les résultats confirment les différences entre les aires de connaissance, ils indiquent aussi l'importance de ces mécanismes de financements indispensables pour terminer les cours. On peut confirmer aussi des différences significatives dans chaque cours quant aux résultats associés à chaque type de bourse et de prêt.

MotS-CLÉs: enseignement supérieur, domaines de la connaissance, égalités de chance, prêts et bourses.

Maria Ligia de Oliveira Barbosa - Doutora em Ciências Sociais pela Universidade Estadual de Campinas. Professor adjunto da Universidade Federal do Rio de Janeiro. Tem experiência na área de Sociologia, com ênfase em Sociologia da Educação, atuando principalmente nos seguintes temas: desigualdades sociais, hierarquias sociais e profissões, políticas educacionais. Vice-Presidente para América Latina do RC04 - Sociology of Education - da ISA (International Sociological Association) 2010-2014. Publicações recentes: A educação e os processos sociais de organização das desigualdades Introdução. Estudos de Sociologia. São Paulo, v. 15, p. 15-18, 2010; O espaço urbano na escola: efeitos sobrea distribuição da qualidade. Sociologia da Educação, v. 01, p. 40-70, 2010; Dossiê: a educação e os processos sociais de organização das desigualdades. Araraquara: UNESP, 2010. v. 01.112 p.

Clarissa Tagliari Santos - Mestre em Sociologia e Antropologia pela Universidade Federal do Rio de Janeiro. Pesquisadora do Laboratório de Pesquisa em Desigualdade Social e Educação, tendo experiência na área de Sociologia, com ênfase em Sociologia da Educação. 